\title{
Design selective band antenna using coupling sidewall and multi resonator for wireless communications
}

\author{
Ali Khalid Jassim ${ }^{1}$, Malik Jasim Farhan², Alaa Fadhil Fahad ${ }^{3}$ \\ ${ }^{1,2}$ Electrical Engineering Department, College Engineering, Mustansiriyah University, Iraq \\ ${ }^{3}$ Ministry of Health and Environment, Iraq
}

\section{Article Info \\ Article history: \\ Received Feb 16, 2020 \\ Revised May 4, 2020 \\ Accepted Jun 15, 2020}

\section{Keywords:}

Resonator

Return loses

Sidewall

Tuned

WBPF

\begin{abstract}
Design and simulation of antenna with performance operating at bandwidth (4.5-6.5) GHz, with center frequency $5.5 \mathrm{GHz}$. This antenna constriction from two cylindrical antenna shapes and four cylindrical resonators with include iris to matching impedance, to enhancement sharp edge band and four tuned between coupling sidewall to removed distortions. Improving the frequency selection of the bandwidth requirement antenna is by adjusting the cylinder length of the antenna The proposed antenna is operating ideal filter because the edge of the band rejection is matched the edge of the bandwidth requirement which makes it perform well including broad edges for the band rejection and sharp edges of the bandwidth requirement together with a little insertion between two types and good return loss of the bandwidth requirement. CST software used to investigate and simulated results.
\end{abstract}

This is an open access article under the CC BY-SA license.

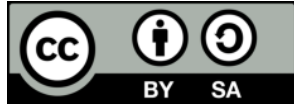

\section{Corresponding Author:}

Ali Khalid Jassim,

Department of Electrical Engineering,

Mustansiriyah University, Iraq.

Email: alijassim79@yahoo.com

\section{INTRODUCTION}

Recently, wireless communication devices and systems must be high performance, small in size and easy to use, and they have wide bandwidth, few losses, and high efficiency, as well as the selectivity of radio waves very high [1]. The significant growth and development in modern wireless communications, which has resulted in increased spectrum congestion, which has given great importance to the use of microstrip (wideBPF) in its use in communication systems [2]. Usually, the receivers and transmitters operate on more than one band, and therefore the need is necessary for antenna worker a bandpass filter (BPF) that works on a specific bandwidth, which allows the passage of wanted frequencies and prevents other frequencies, so broadband servers can be implemented [3-5]. The second harmonic causes several problems in responding to the filter antenna when using traditional filter antenna designs. Therefore, many filters antenna are designed in different ways that avoid harmonics. When performing a filter antenna, it must have a wideband and the signal selection is very high [6-10].

In this work, the antenna is operated a wide passband filter type is proposed, which is characterized by a high selectivity of the required band, which consists of two cylindrical antennas at the two ends of the filter and between them four resonators to improve matching and four tunes for toning and deformation removal, as well as the presence of separating walls between stages that achieve response to bandwidth. It is possible to control the cylindrical tunes and resonators by sending four zeros which give the band a good broad as it works on the upper of the band to improve the selection of the passband as well as they reject of the band stop, and this filter was made of FR4. 


\section{RESEARCH METHOD}

The proposed antenna is shown in Figure 1 is easy to implement, which is represented by a simple, identical size microscope line, easy to build that gives a wide band and is compatible with the bandpass filter and band stop filter and works in WiMAX and WLAN applications. The designed antenna has four identical parallel-coupled cylindrical tuned and resonator at the desired center frequency, three tuners between iris to remove distortion in the cavity model. Table 1 shows the parameter antenna design.

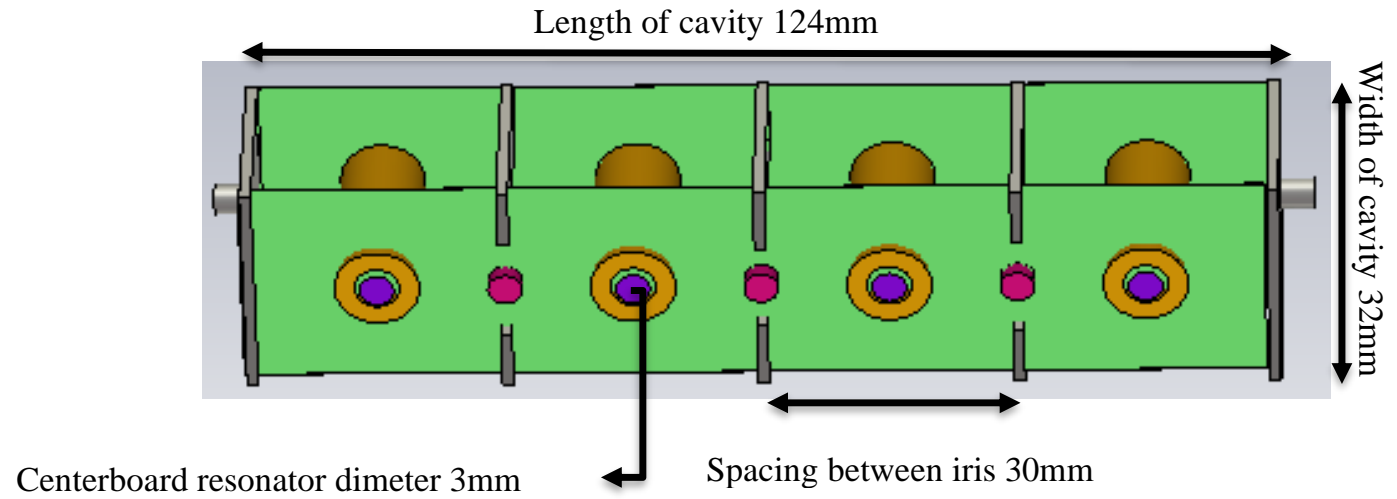

(a)

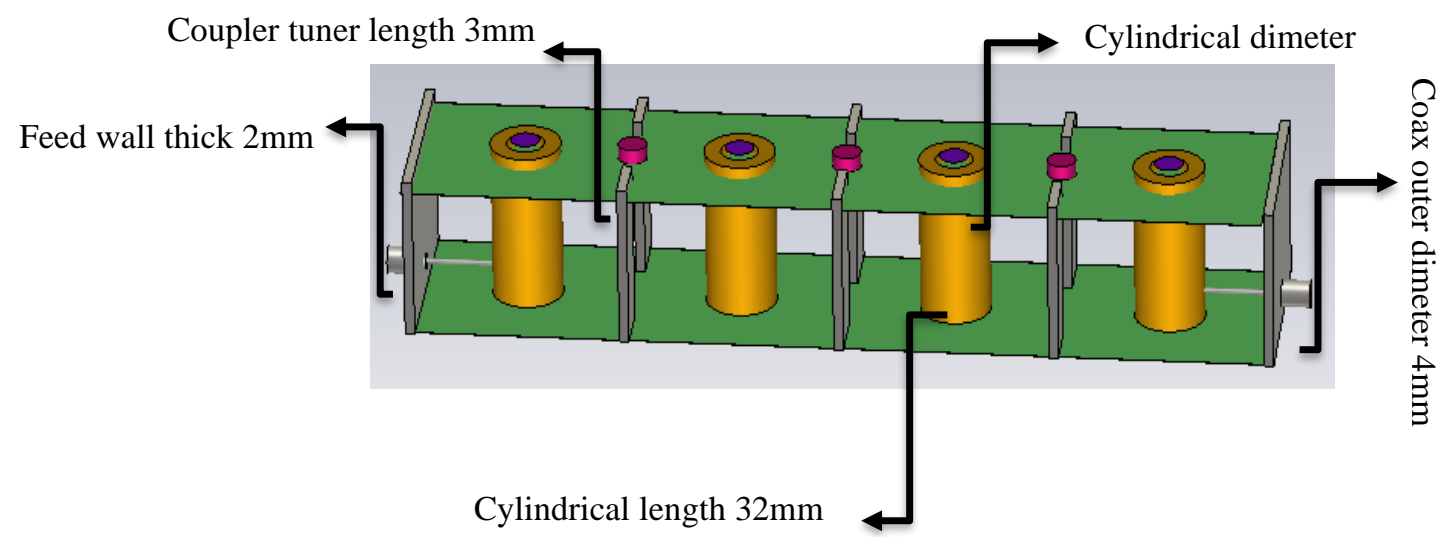

(b)

Figure 1. The proposed antenna, (a) Perspective, (b) Bottom

Table 1. Parameter filter design

\begin{tabular}{cccc}
\hline Parameter & Value in $(\mathrm{mm})$ & Parameter & Value in $(\mathrm{mm})$ \\
\hline LC & 124 & WC & 32 \\
CRD & 3 & CTL & 3 \\
SBI & 30 & CD & 15 \\
COD & 4 & CL & 32 \\
FWT & 2 & & \\
\hline
\end{tabular}

In this proposed antenna, a multi-mode resonator is used in a multi-cylinder resonator, and you need the first three resonance frequencies. Figure 2(a) shows the open circuit represents steppe impedance for the multi-mode resonator and Figure 2(b) shows transmission line circuit model. In the MCR-based used in proposed filters antenna, the different resonator modes are used, point to form a single WBP. Normalize resonance frequencies against impedance rate $\left(\mathrm{R}=\mathrm{Z}_{2} / \mathrm{Z}_{1}\right)$ of a multi-mode resonator. Such as has always been completed before based on generalized transmission line theory, the multiple-mode property of the MCR can be described simply [11-15]. Figure 2(b) the total transmission line circuit model, where the terminal ends of this multiple-mode resonator MMR are both open circuit [16, 17]. 


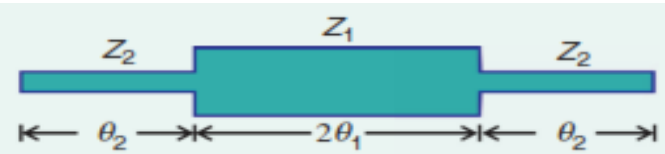

(a)

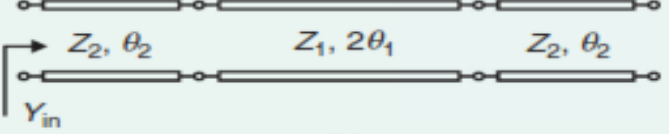

(b)

Figure 2. (a) The open circuit represents the steppe impedance multimode resonator, (b) The total transmission line circuit model

Can be derived the input admittance $\left(Y_{\text {in }}\right)$ in the following [18-25]:

$$
Y_{\text {in }}=j Y_{2} \frac{2\left(R \tan \theta_{1}+\tan \theta_{2}\right)\left(R-\tan \theta_{1} \tan \theta_{2}\right)}{R\left(1-\tan ^{2} \theta_{1}\right)\left(1-\tan ^{2} \theta_{2}\right)-2\left(1+R^{2}\right) \tan \theta_{1} \tan \theta_{2}}
$$

where $\left(\mathrm{R}=\mathrm{Z}_{2} / \mathrm{Z}_{1}\right)$ is the impedance ratio.

At the resonances, we have:

$$
Y_{\text {in }}=0
$$

From (1) and (2), can be determined a group of resonance frequencies $\left(f_{1}, f_{2}, \ldots\right)$ from $\theta_{1}$ and $\theta_{2}$. In the case of $\theta_{2}=2 \theta_{1}=\theta$ we have:

$$
\begin{aligned}
& \theta\left(f_{1}\right)=\tan ^{-1} \sqrt{\frac{R}{R+2}} \\
& \theta\left(f_{2}\right)=\tan ^{-1} \sqrt{\frac{R+2}{R}} \\
& \theta\left(f_{3}\right)=\frac{\pi}{2}
\end{aligned}
$$

Therefore,

$$
\begin{aligned}
& \frac{\mathrm{f}_{2}}{\mathrm{f}_{1}}=\frac{\theta\left(\mathrm{f}_{2}\right)}{\theta\left(\mathrm{f}_{1}\right)}=\frac{\tan ^{-1} \sqrt{\frac{\mathrm{R}+2}{\mathrm{R}}}}{\tan ^{-1} \sqrt{\frac{\mathrm{R}}{\mathrm{R}+2}}} \\
& \frac{f_{3}}{f_{1}}=\frac{\theta\left(f_{3}\right)}{\theta\left(f_{1}\right)}=\frac{\pi}{2 \tan ^{-1} \sqrt{\frac{R}{R+2}}}
\end{aligned}
$$

In the analysis for the case of $\theta_{2}=\theta_{1}=\theta$, can be obtained from (3-7) respectively.

$$
\begin{aligned}
& \theta\left(f_{1}\right)=\tan ^{-1} \sqrt{R} \\
& \theta\left(f_{2}\right)=\frac{\pi}{2} \\
& \theta\left(f_{3}\right)=\pi-\tan ^{-1} \sqrt{R} \\
& \theta\left(f_{4}\right)=\pi
\end{aligned}
$$

Therefore,

$$
\frac{\mathrm{f}_{2}}{\mathrm{f}_{1}}=\frac{\pi}{2 \tan ^{-1} \sqrt{\frac{\mathrm{R}}{\mathrm{R}+2}}}
$$




$$
\begin{aligned}
& \frac{\mathrm{f}_{3}}{\mathrm{f}_{1}}=\frac{\pi}{\tan ^{-1} \sqrt{\frac{\mathrm{R}}{\mathrm{R}+2}}}-1 \\
& \frac{\mathrm{f}_{4}}{\mathrm{f}_{1}}=\frac{\pi}{\tan ^{-1} \sqrt{\mathrm{R}}}
\end{aligned}
$$

These three normalized frequencies in (12-14) are similar when used the case $\theta_{2}=2 \theta_{1}=\theta$, the fourth frequency is distinguished from the first three frequencies of the resonance, where the first frequencies are close to each other by increasing the resistance.

\section{RESULT AND DISCUSSION}

The antenna is operated filter to select band WiMAX and WiLAN require can be obtained. To achieve a narrow coupling, a slot width in the resonator must be reduced. A parallel coupling microstrip line (PCML) has been used extensively in the multi-stage design of the bandwidth requirement.

Figure 3 shows the simulation result of $S_{11}$ represents the bandpass filter at the bandwidth (4.5-6.5) $\mathrm{GHz}$ to have center frequency $5.5 \mathrm{GHz}$, and $\mathrm{S}_{21}$ represents the ideal bandstop filter for the bandwidth requirement.

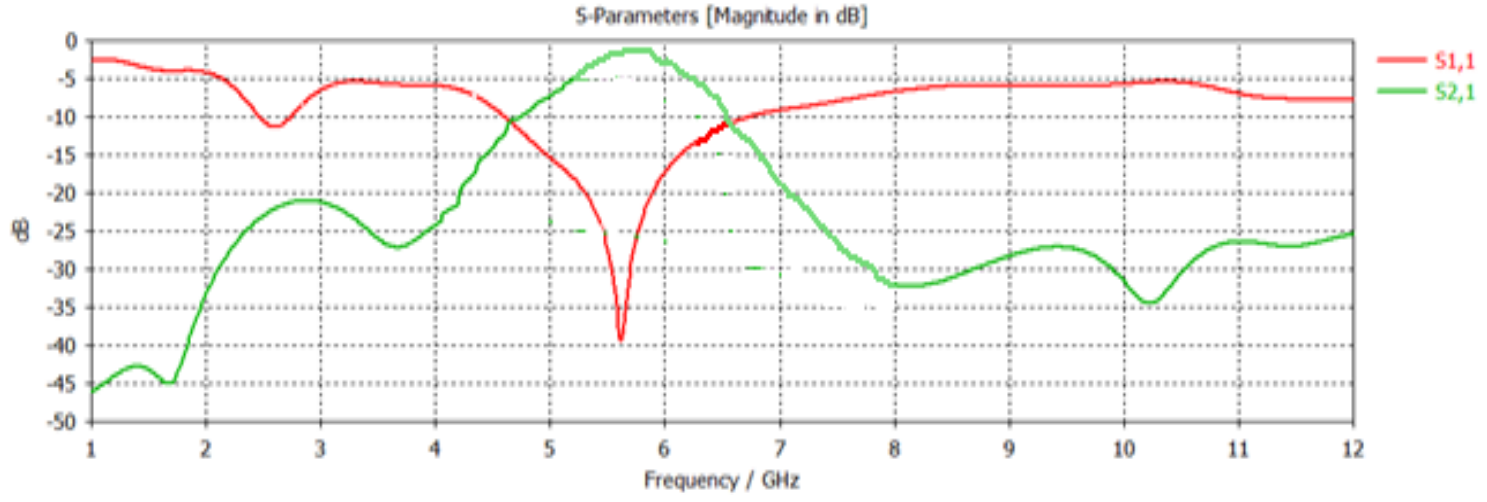

Figure 3. Simulated frequency response of $S_{11}$ and $S_{21}$

Figure 4 shows the group time delay of the antenna designed should be able to transmit the electrical pulse with minimum distortion is calculated of the proposed filter is around to zero with variation is $(0$ to -2$)$ nsec due the bandwidth frequency $(4.5-6.5) \mathrm{GHz}$ and the voltage standing wave ratio (VSWR) is also less than $\leq 2$ as shown in Figure 5 so that the VSWR is the ratio of maximum voltage or current to minimum voltage or current at any point it considers as measure for the mismatch between the line and the load.

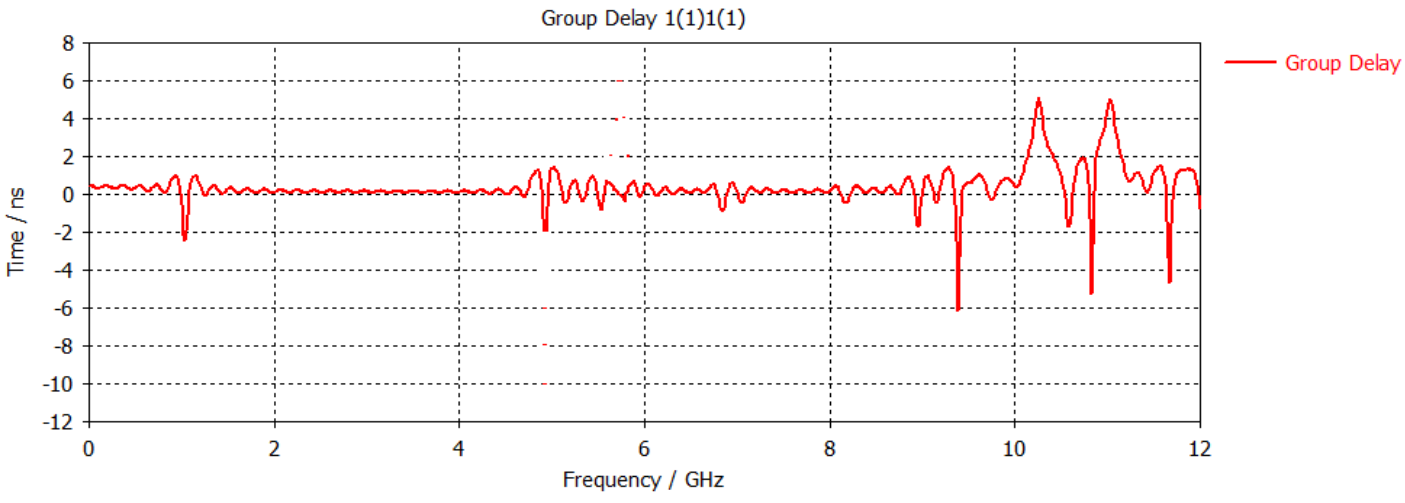

Figure 4. Group delay at frequency $5.5 \mathrm{GHz}$ 


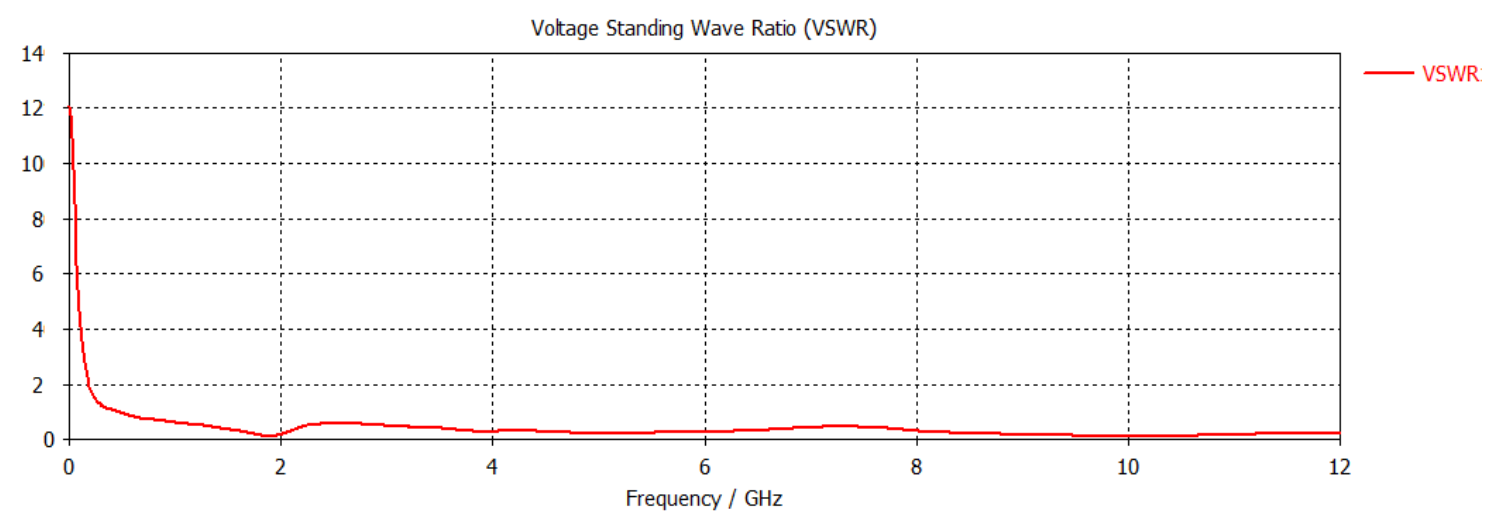

Figure 5. Voltage standing wave ratio at $5.5 \mathrm{GHz}$

Figure 6 shows the real filter input impedance value equal to $50 \mathrm{ohms}$ at $5.5 \mathrm{GHz}$ and Figure 7 shows the imaginary filter input impedance value equal zero at $5.5 \mathrm{GHz}$. The gain at the frequency resonance requirement is $7 \mathrm{dBi}$ as shown in Figure 8. The radiation pattern is stable at $5.5 \mathrm{GHz}$ where the frequency bandwidth changes with nearly omnidirectional radiation pattern. Figure 9 show the simulated radiation pattern in E-plan and H-Plan for the frequency requirement, show good approval. Both planes for the antenna show two independent orthogonal linear polarizations so the separation two directions (X and Y). Nearly good omnidirectional patterns have been observed.

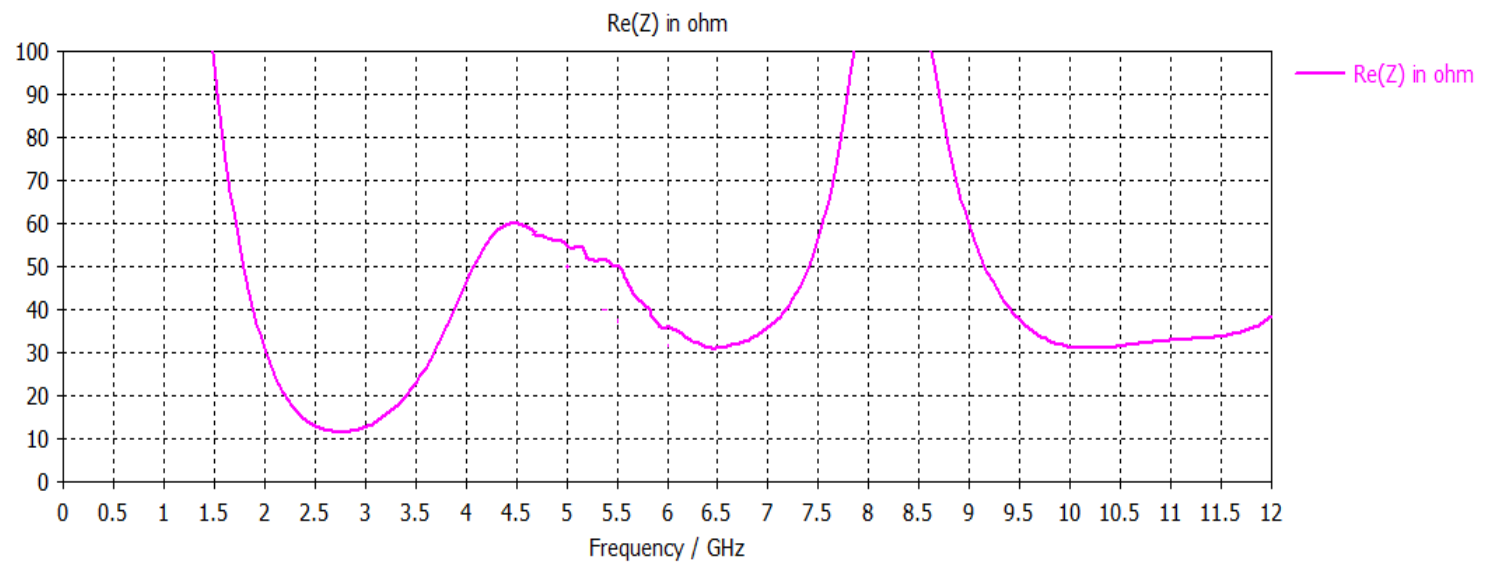

Figure 6. The real impedance value at $5.5 \mathrm{GHz}$

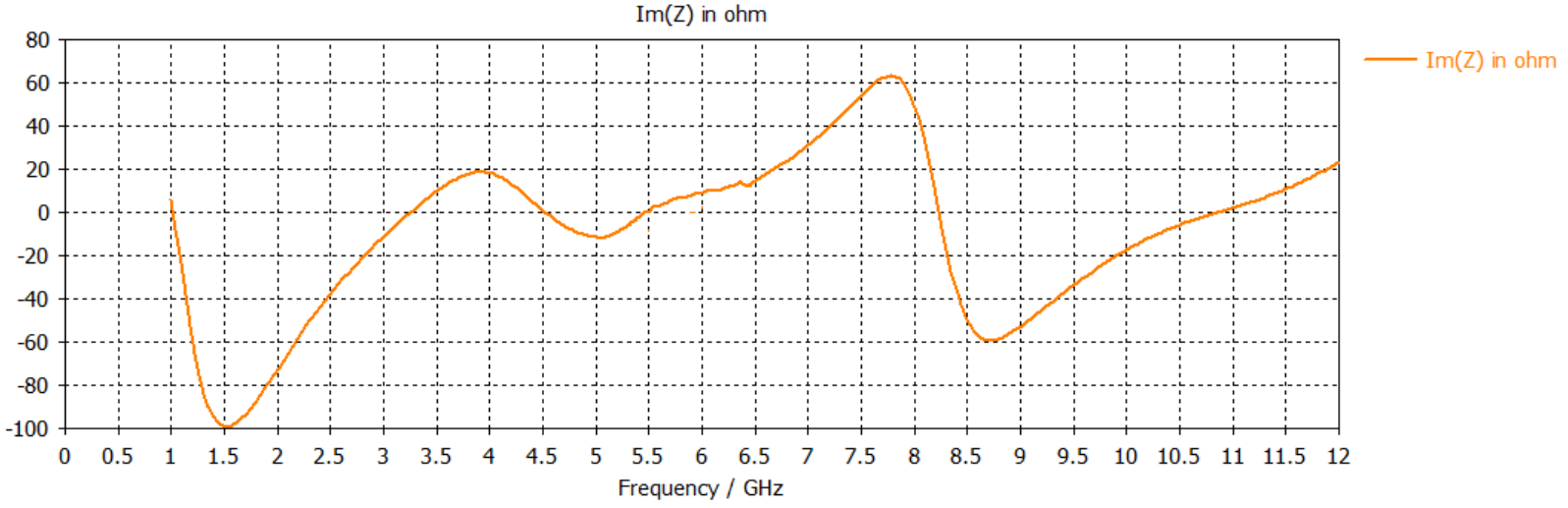

Figure 7. The imaginary impedance value at $5.5 \mathrm{GHz}$ 


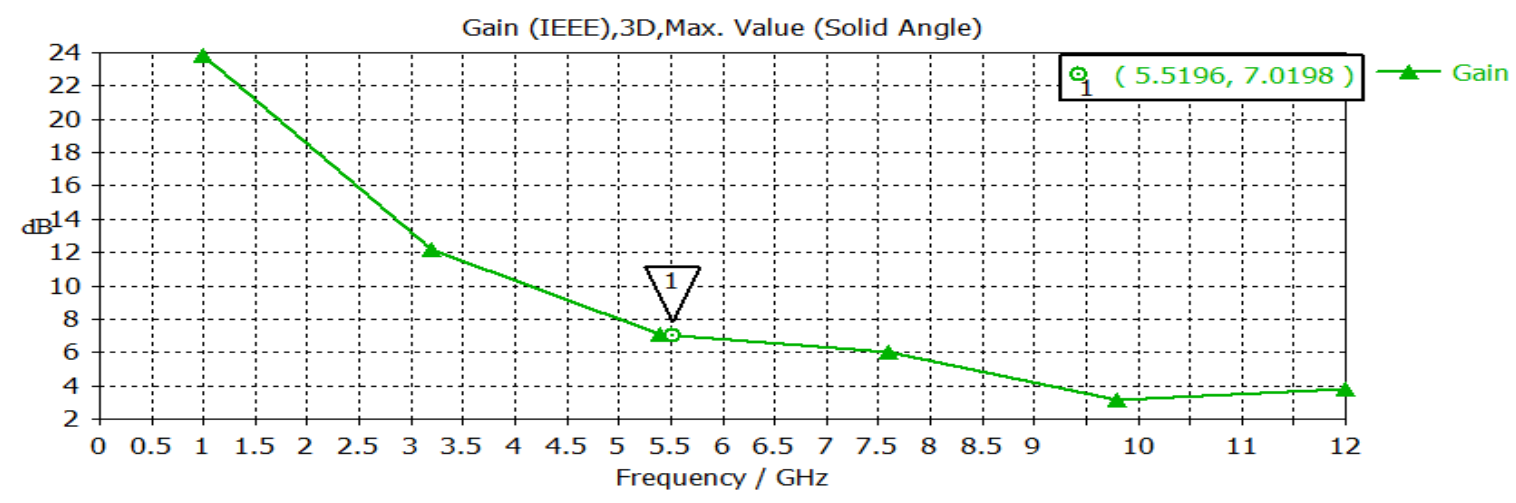

Figure 8. The gain value at $5.5 \mathrm{GHz}$

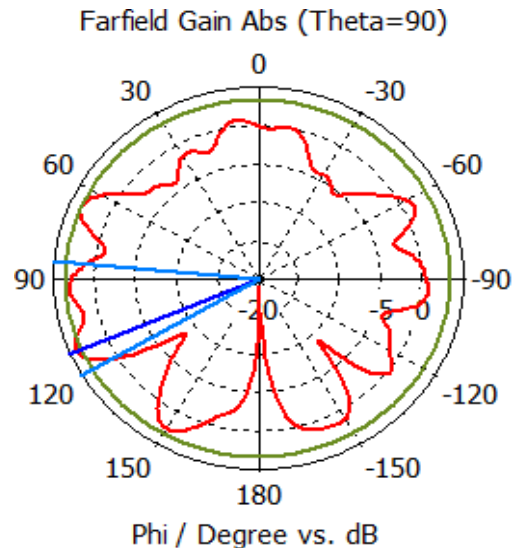

Figure 9. The radiation patterns of proposed filter antenna in E-plane \& $\mathrm{H}$-plane at $\mathrm{f}=5.5 \mathrm{GHz}$

\section{CONCLUSIONS}

Antenna design with an inserted bandwidth from selective frequency is given to (4.5-6.5) $\mathrm{GHz}$ with frequency center $5.5 \mathrm{GHz}$. The antenna proposed size is $(124 \times 32 \times 32) \mathrm{mm}$. The simulation results of the reflection coefficient of the proposed antenna are $-38 \mathrm{~dB}$ return-loss at the bandwidth requirement and co-reflection coefficient for the band-reject $-1 \mathrm{~dB}$, at the WiMAX and WLAN application. The proposed antenna effectively addresses frequency interference problems and has comprehensive properties in coverage in all directions as well as stable and stable characteristics in the reception and transmission of signals and can be built and designed easily and its properties can be modified with high flexibility and that this antenna is operated filter is compatible with WiMAX and WLAN applications.

\section{ACKNOWLEDGMENTS}

The authors acknowledge support from the authority of Mustansiriyah University. The authors would like to give special thanks to the anonymous referee for suggesting several pertinent issues that have enabled us to improve the manuscript substantially.

\section{REFERENCE}

[1] D. F. Williams and S. E. Schwarz, "Design and Performance of Coplanar Waveguide Bandpass Filters," in IEEE Transactions on Microwave Theory and Techniques, vol. 31, no. 7, pp. 558-566, Jul. 1983.

[2] Ching-Luh Hsu, Fu-Chieh Hsu and J. -. Kuo, "Microstrip bandpass filters for Ultra-Wideband (UWB) wireless communications," IEEE MTT-S International Microwave Symposium Digest, 2005., Long Beach, CA, pp. 679-682, 2005.

[3] M. K. Mandal and S. Sanyal, "Compact wideband bandpass filter," in IEEE Microwave and Wireless Components Letters, vol. 16, no. 1, pp. 46-48, Jan. 2006.

[4] A. M. Abbosh, "Planar Bandpass Filters for Ultra-Wideband Applications," in IEEE Transactions on Microwave Theory and Techniques, vol. 55, no. 10, pp. 2262-2269, Oct. 2007. 
[5] A. Saito, H. Harada and A. Nishikata, "Development of band pass filter for ultra wideband (UWB) communication systems," IEEE Conference on Ultra Wideband Systems and Technologies, 2003, Reston, VA, USA, pp. 76-80, 2003.

[6] Lung-Hwa Hsieh and Kai Chang, "Compact, low insertion-loss, sharp-rejection, and wide-band microstrip bandpass filters," in IEEE Transactions on Microwave Theory and Techniques, vol. 51, no. 4, pp. 1241-1246, April 2003

[7] A. K. Jassim and R. H. Thaher, "Design and Analysis of broadband Elliptical Microstrip Patch Antenna for Wireless Communication," TELKOMNIKA Telecommunication Computing Electronics and Control, vol. 16, no. 6, pp. 2492-2499, December 2018.

[8] Lei Zhu, Sheng Sun and W. Menzel, "Ultra-wideband (UWB) bandpass filters using multiple-mode resonator," in IEEE Microwave and Wireless Components Letters, vol. 15, no. 11, pp. 796-798, Nov. 2005

[9] Jing Gao, Lei Zhu, W. Menzel and F. Bogelsack, "Short-circuited CPW multiple-mode resonator for ultrawideband (UWB) bandpass filter," in IEEE Microwave and Wireless Components Letters, vol. 16, no. 3, pp. 104-106, March 2006.

[10] N. Thomson and J. Hong, "Compact Ultra-Wideband Microstrip/Coplanar Waveguide Bandpass Filter," in IEEE Microwave and Wireless Components Letters, vol. 17, no. 3, pp. 184-186, March 2007.

[11] Ali Khalid Jassim, Raad H. Thaher, "Enhancement Gain of broadband Elliptical Microstrip Patch Array Antenna with Mutual Coupling for Wireless Communication" Indonesian Journal of Electrical Engineering and Computer Science, vol. 13, no. 1, pp. 217-225, January 2019.

[12] J. -. Kuo and E. Shih, "Microstrip stepped impedance resonator bandpass filter with an extended optimal rejection bandwidth," in IEEE Transactions on Microwave Theory and Techniques, vol. 51, no. 5, pp. 1554-1559, May 2003.

[13] M. K. A. Rahim, M. N. A. Karim, T. Masri and A. Asrokin, "Comparison between Straight and U shape of Ultra Wide Band Microstrip Antenna using Log Periodic Technique," 2007 IEEE International Conference on UltraWideband, Singapore, pp. 696-699, 2007.

[14] Ali Khalid Jassim, Raad H. Thaher, "Calculate the optimum slot area of the elliptical microstrip antenna for mobile applications," Indonesian Journal of Electrical Engineering and Computer Science (IJEECS), vol. 16, no. 3, pp. 1364-1370, December 2019.

[15] M. H. Badjian, C. K. Chakrabarty, G. C. Hock and S. Devkumar, "An Impulse UWB Patch Antenna with Integrated Bandpass Filter," 2008 6th National Conference on Telecommunication Technologies and 2008 2nd Malaysia Conference on Photonics, Putrajaya, pp. 166-169, 2008.

[16] G. Brzezina, Qiubo Ye and L. Roy, "Development of a practical ultra-wideband antenna with planar circuit integration possibilities," 2005 IEEE Antennas and Propagation Society International Symposium, Washington, DC, pp. 504-507 vol. 3A, 2005.

[17 Lee Chia Ping, Chandan Kumar Chakrabarty, Rozanah Amir Khan, "Enhanced Bandwidth of Impulse-Ultra Wideband (I-UWB) Slotted Rectangular Patch Antenna with Partial Ground Plane," International Journal of Electronics, Computer and Communications Technologies (IJECCT), vol. 1, no. 1, pp. 21-25, 2010.

[18] Ali Khalid Jassim, and Raad H. Thaher, "Design of MIMO (4x4) Broadband Antenna Array for mm-wave Wireless Communication Applications," International Journal on Engineering Applications (IREA), vol. 07, no. 2, pp. 65-71, 2019.

[19] M. Kumar, A. Basu, and S. K. Koul, "UWB Printed Slot antenna with improved performance in time and frequency domain," in Progress In Electromagnetics Research C, vol. 18, pp. 197-210, 2011.

[20] H. G. Schantz, "A brief history of UWB antennas," in IEEE Aerospace and Electronic Systems Magazine, vol. 19, no. 4, pp. 22-26, April 2004.

[21] R. Azim, A. T. Mobashsher, M. T. Islam and N. Misran, "Compact planar antenna for UWB applications," 2010 International Conference on Microwave and Millimeter Wave Technology, Chengdu, 2010, pp. 1987-1990.

[22] H. Liu, C. Ku, T. Wang and C. Yang, "Compact Monopole Antenna With Band-Notched Characteristic for UWB Applications," in IEEE Antennas and Wireless Propagation Letters, vol. 9, pp. 397-400, 2010.

[23] A. Safarian and P. Heydari, "Silicon-Based RF Front-Ends for Ultra Wideband Radios," Springer Netherlands, 2007.

[24] P. S. Hall, P. Gardner and A. Faraone, "Antenna Requirements for Software Defined and Cognitive Radios," in Proceedings of the IEEE, vol. 100, no. 7, pp. 2262-2270, July 2012.

[25] Abdullah A. Jabber, Ali Khalid Jassim, Raad H. Thaher, "Compact reconfigurable PIFA antenna for wireless applications," TELKOMNIKA Telecommunication, Computing, Electronics and Control, vol. 18, no. 2, pp. 595-602, April 2020. 